\title{
Original
}

Journal of Hard Tissue Biology 24[4] (2015) 341-346

\section{Bone Adaptation of Fibronectin-Immobilized Titanium Implants Using a Tresyl Chloride-Activated Method}

\author{
Masatsugu Hirota' $^{1)}$, Hidemasa Shimpo ${ }^{2)}$, Chikahiro Ohkubo'), Tetsushi Umegaki ${ }^{3)}$, \\ Takeshi Toyama ${ }^{3)}$ and Tohru Hayakawa ${ }^{1)}$
}

\author{
${ }^{1)}$ Department of Dental Engineering, Tsurumi University School of Dental Medicine, Yokohama, Japan \\ 2) Department of Removable Prosthodontics, Tsurumi University School of Dental Medicine, Yokohama, Japan \\ ${ }^{3)}$ Department of Materials and Applied Chemistry, College of Science and Technology, Nihon University, Tokyo, Japan \\ (Accepted for publication, July 7, 2015)
}

\begin{abstract}
The aim of the present study was to evaluate the bone adaptation of fibronectin-immobilized titanium implants in vivo using a tresyl chloride-activated method in implantation experiments with rabbit tibiae. Cylindrical pure titanium $(3.5 \mathrm{~mm}$ in diameter and $7 \mathrm{~mm}$ in height $)$ was treated with tresyl chloride $(2,2,2-$ trifluoroethanesulfonyl chloride, $\mathrm{CF}_{3} \mathrm{CH}_{2} \mathrm{SO}_{2} \mathrm{Cl}$ ) and then coupled with fibronectin to give fibronectinimmobilized cylindrical titanium (Fn/Ti) implants. Non-treated cylindrical titanium (Ti) implants were used as a control. Ti and $\mathrm{Fn} / \mathrm{Ti}$ implants were implanted into bone defects in the tibiae of rabbits. The implants were excised 12 weeks later and non-decalcified thin sections were prepared. After staining each section with methylene blue and basic fuchsin, the implant-bone interface was histologically evaluated and the bone-to-implant contact ratio (BIC) and bone mass (BM) were histomorphometrically calculated using an image analysis system. A larger amount of new bone formation was recognized for $\mathrm{Fn} / \mathrm{Ti}$ implants and histomorphometrical evaluations showed that BIC and BM were significantly higher for $\mathrm{Fn} / \mathrm{Ti}$ implants than for Ti implants. Fn/Ti implants also showed better bone adaptation. These results demonstrated that the immobilization of fibronectin onto cylindrical titanium implants effectively enhanced bone regeneration around implants.
\end{abstract}

Key words: Titanium implant, Fibronectin, Tresyl chloride, Osteoblast, Bone-to-implant contact

\section{Introduction}

In the last few years, several studies have been devoted to investigating surface modifications to titanium dental implants. Various surface modifications to titanium implants have been postulated to improve the bone healing response. For example, sandblasting ${ }^{1)}$, alkali treatments ${ }^{2)}$, anodizing ${ }^{3)}$, laser irradiation ${ }^{4)}$, micro-arc oxidation ${ }^{5}$, and hydroxyapatite coating ${ }^{6}$ were previously identified as effective surface modifications.

Biochemical surface modifications have been attracting increasing attention. The extracellular matrix, cell adhesive proteins, or cytokines have been coated or immobilized onto titanium surfaces ${ }^{7}$. Previous studies reported that a fibronectin, laminin, or collagen coating on titanium implants effectively enhanced new bone formation ${ }^{8-11)}$.

However, proteins have merely been coated and not adhered chemically with covalent binding on titanium substrates. During implantation, the implant body is strongly torqued and drilled into hard bone. The tight bonding of biomolecules to titanium is desired

Correspondence to: Dr. Masatsugu Hirota, 2-1-3 Tsurumi, Tsurumi-ku, Yokohama, Kanagawa, 230-8501 Japan; Phone: +81-45-580-8369; Fax: +81-45-573-9599; E-mail: hirota-masatsugu@tsurumi-u.ac.jp by dental implant clinics. Culp et al. ${ }^{12)}$ examined the chemical immobilization of fibronectin to titanium surfaces using a silane coupling agent. In contrast, Hayakawa et al. ${ }^{13)}$ developed an easy method for immobilizing proteins or cytokines onto a titanium surface, named the tresyl chloride-activated method. This method is a modification of that previously reported by Nilsson and Mosback ${ }^{14}$. This technique is very simple, inexpensive, and does not require special facilities. The immobilization scheme was shown in Fig. 1. Basic terminal hydroxyl groups on the titanium surface were reacted with tresyl chloride and tresyl chlorideactivated titanium was coupled with proteins or cytokines. A quartz-crystal microbalance technique and molecular orbital calculation for the model compound suggested the mechanism underlying tresyl chloride-activated methods ${ }^{15-17)}$. Fibronectin or collagen immobilization onto titanium has been shown to enhance initial cell attachment ${ }^{18}$. The arrangements of attached cells were also found to be influenced by fibronectin immobilization ${ }^{19)}$. The gene expression levels of some genes related to the mineralization process were reported to be up-regulated during an osteoblastlike cell assay on fibronectin or GRGDSP peptide-immobilized titanium ${ }^{20)}$. Alkaline phosphatase or transforming growth factor 


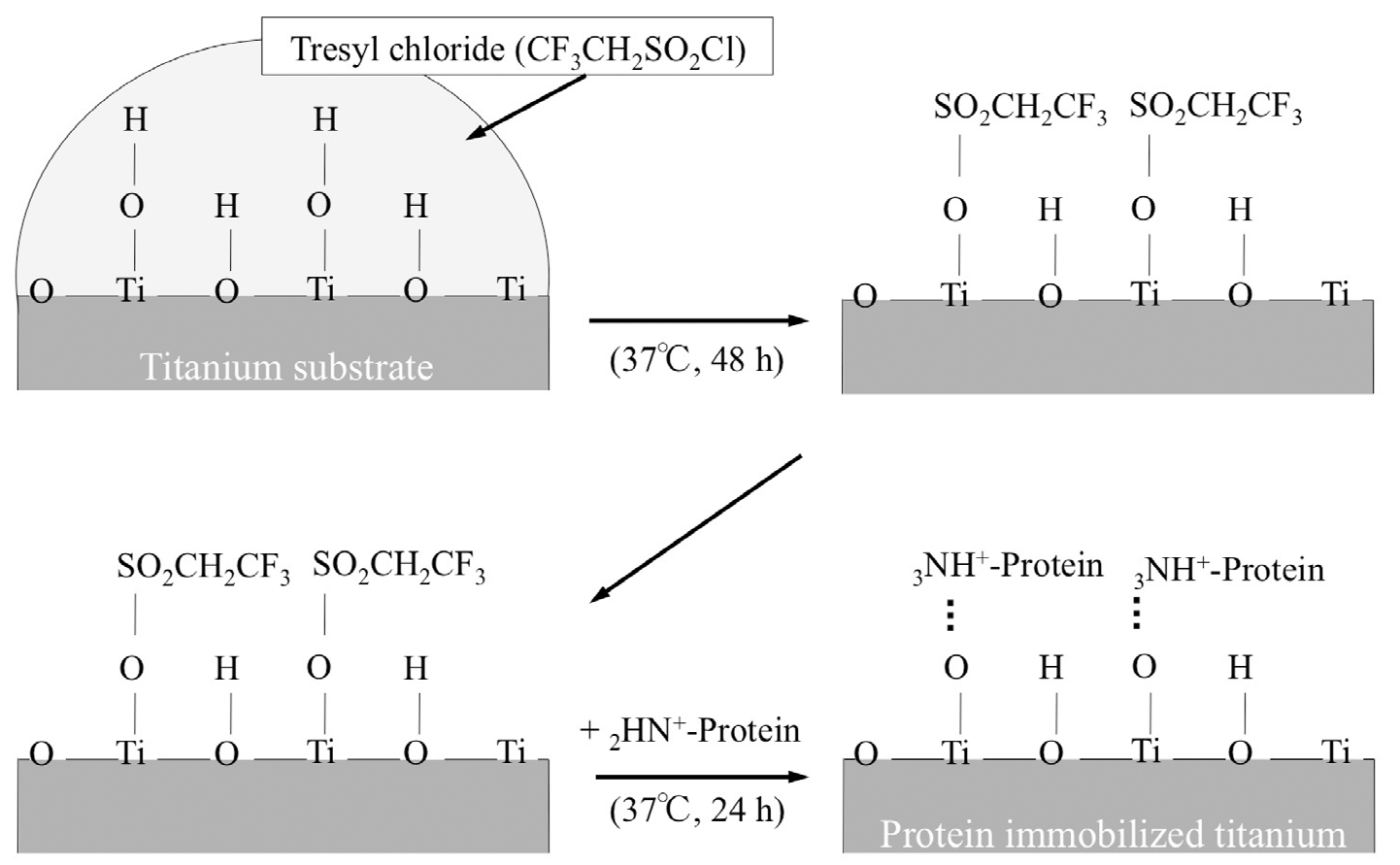

Figure 1. Schematic drawing of protein immobilization using the tresyl chloride-activation method

(TGF- $\beta$ ) has also been immobilized onto titanium using the tresyl chloride-activated method ${ }^{21,22)}$, and the immobilization of TGF$\beta 2$ was shown to enhance bone regeneration around implants.

The aim of the present study was to evaluate the bone adaptation of fibronectin-immobilized titanium implants using the tresyl chloride-activated technique in implantation experiments with rabbit tibiae.

\section{Materials and Methods}

\section{Titanium substrate}

Pure titanium cylindrical implants (Ti cylinder; 99.9 mass \% Ti, Grade 2, $3.5 \mathrm{~mm}$ in diameter and $7.0 \mathrm{~mm}$ in height, Furuuchi Chemical Co., Tokyo, Japan) were used after ultrasonically cleaning in ethanol and distilled water.

\section{Fibronectin immobilization by the tresyl chloride-activated method}

Fibronectin was immobilized onto the cylindrical titanium implant surface using the previously described tresyl chlorideactivated technique ${ }^{13)}$. Tresyl chloride (2,2,2trifluoroethanesulfonyl chloride, $\mathrm{CF}_{3} \mathrm{CH}_{2} \mathrm{SO}_{2} \mathrm{Cl}$, Fluka, Buchs, Switzerland) was dropped on the cylindrical Ti implant surface from the top to bottom in order to cover the entire area completely. Treated cylindrical Ti implants were then stored at $37^{\circ} \mathrm{C}$ for $48 \mathrm{~h}$. Tresylated Ti implants were washed with acetone followed by a water: water-acetone solution (50: 50), then dried and stored in a desiccator. Fibronectin (Upsatate Biotechnology, Lake Placid, NY,

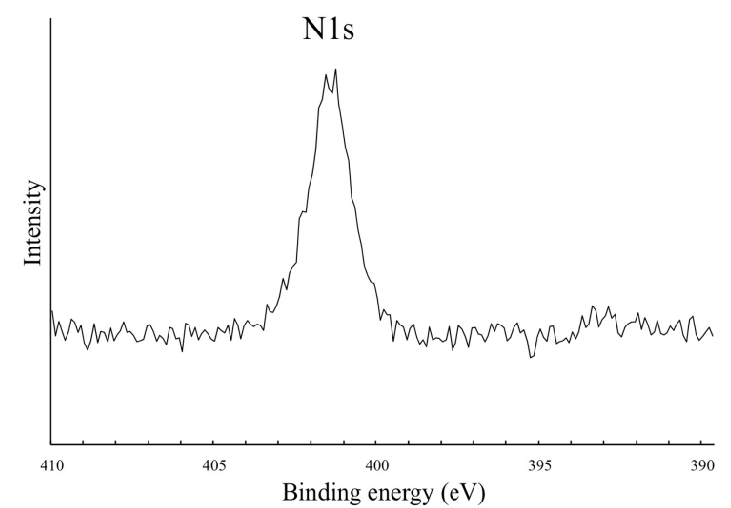

Figure 2. N1s spectra of the Fn/Ti surface by a XPS analysis

USA) was dissolved at a concentration of $0.1 \mathrm{mg} / \mathrm{ml}$ in double distilled water. Tresylated Ti implants were dipped into fibronectin solution and stored at $37^{\circ} \mathrm{C}$ for $24 \mathrm{~h}$. After rinsing with double distilled water, fibronectin-immobilized cylindrical Ti implants were stored in a desiccator at room temperature. Fibronectinimmobilized cylindrical titanium (Fn/Ti) implants were used as the experimental group, whereas non-treated cylindrical $\mathrm{Ti}$ implants were employed as the control group.

\section{Characterization of the Fn/Ti cylinder}

A titanium disk (99.9 mass \% Ti, Grade 2, $5.5 \mathrm{~mm}$ in diameter and $1.0 \mathrm{~mm}$ in thickness, Furuuchi Chemical Co., Tokyo, Japan) was used to characterize fibronectin on the titanium surface. The 

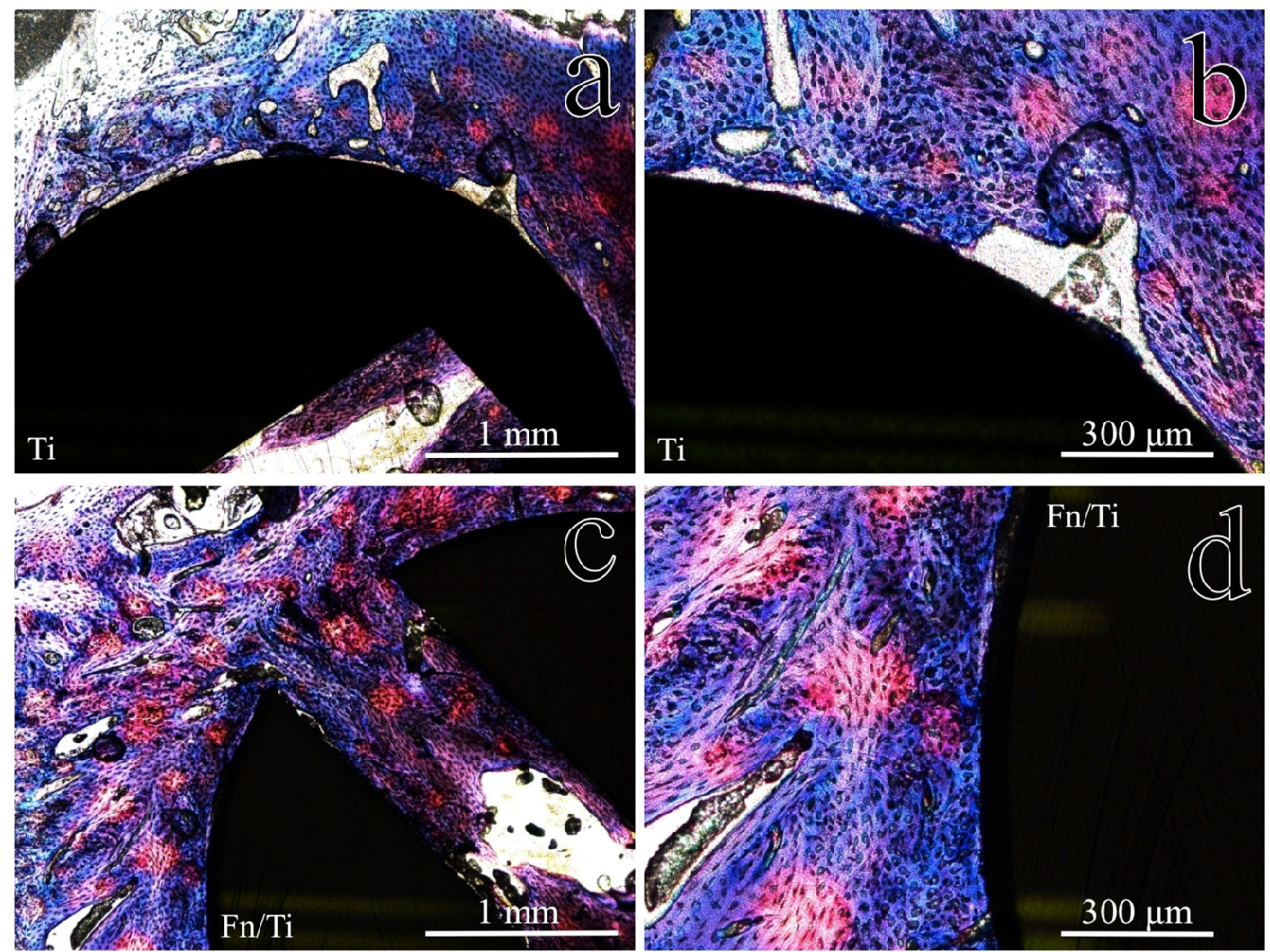

Figure 3. Histological appearances of cylindrical Ti and $\mathrm{Fn} / \mathrm{Ti}$ implants 12 weeks after their implantation into bone defects in the rabbit tibia. (a), (b) Ti implant; (c), (d) Fn/Ti implant.

Ti disk was treated with tresyl chloride and coupled with fibronectin as described above to give a fibronectin-immobilized titanium (Fn/Ti) disk. The Fn/Ti disk was characterized using an X-ray photoelectron spectroscope (XPS, ESCA-3400, Shimadzu Corp, Kyoto, Japan) equipped with an $\operatorname{MgK} \alpha \mathrm{X}$-ray source operated at $10 \mathrm{kV}$ and $20 \mathrm{~mA}$. The existence of fibronectin was confirmed by the N1s peak of amide bonds of fibronectin. The binding energy for each spectrum was calibrated against the $\mathrm{C} 1 \mathrm{~s}$ peak at $284.8 \mathrm{eV}$.

\section{Animal experiment}

The animal study was approved by the Animal Experimental Ethical Guidelines of Tsurumi University School of Dental Medicine (certificate no. 12018). Prior to surgery, non-treated Ti and Fn/Ti implants were sterilized using ethylene oxide gas. Cylindrical implants were placed in the cortical bone of the left and right tibiae according to a previously described procedure ${ }^{6}$. Each rabbit received one Ti and one Fn/Ti implant (one in the left and the other in the right). A total of 6 implants, $3 \mathrm{Ti}$ and $3 \mathrm{Fn} / \mathrm{Ti}$ implants, were inserted.

Surgery was performed under general inhalation anesthesia with a $5 \%$ isoflurane and oxygen mixture, which was reduced to $2 \%$ isoflurane during surgery. After shaving and disinfecting the operating field, xylocaine was injected as local anesthesia. A longitudinal incision was made on the tibia and the bone was exposed by blunt dissection. A $2.0-\mathrm{mm}$ pilot hole was drilled and the hole was gradually widened to $3.5 \mathrm{~mm}$ using a drilling speed of $800 \mathrm{rpm}$ and continuous internal cooling. Cylindrical Ti or Fn/ Ti implants were inserted into bone defects in the tibia by a press fit. The soft tissue was closed in separate layers using nonabsorbable sutures and a prophylactic antibiotic equivalent to latamoxef sodium $(0.01 \mathrm{mg} / \mathrm{kg}$ Shimalin; Shionogi \& Co., Ltd., Osaka, Japan) was administered to prevent infection. Rabbits were sacrificed 12 weeks after implantation by a peritoneal injection of an overdose of thiamylal sodium (Isothol; Nichi-Iko, Toyama, Japan). The implants and surrounding bone were excised and excess tissue was removed.

\section{Histological and histomorphometrical observations}

After removing the implants and surrounding tissue, specimens were fixed in $10 \%$ buffered formalin solution, dehydrated through a graded series of ethanol, and then embedded in methylmethacrylate. Non-decalcified thin sections with a thickness of approximately $50 \mu \mathrm{m}$ were made in a transverse direction perpendicular to the axis of the implants using a cutting-grinding technique ${ }^{23}$. Sections were stained with methylene blue and basic fuchsin and evaluated using a light microscope (Eclipse $\mathrm{N} i$; Nikon, Tokyo, Japan; magnification $\times 40, \times 100$ ). 
Histomorphometrical evaluations of new bone formation were performed as described in our previous study ${ }^{6}$. The bone-toimplant contact ratio (BIC) and bone mass (BM) around the implant were measured using an image analysis system (WinROOF, Visual System Division; Mitani Corporation, Tokyo, Japan). BM was defined as new bone formation in the region of interest (ROI), which was within the circumference of $110 \%$ of the implant.

\section{Statistical analysis}

The results of $\mathrm{BIC}$ and $\mathrm{BM}$ from histomorphometrical measurements were evaluated by a one-way analysis of variance (ANOVA) and the Bonferroni test for multiple comparisons among the means at $P=0.05$ with SPSS for Windows (SPSS Statics 17.0, SPSS, Chicago, USA).

\section{Results}

\section{Surface characterization}

The surface of the Fn/Ti disk was analyzed by XPS. Fig. 2 shows an XPS narrow scan of the Fn/Ti disk. The N1s peak, derived from the amide bond of immobilized fibronectin, was detected around the binding energy of $400 \mathrm{eV}$.

\section{Histological and histomorphometrical evaluations}

Rabbits remained in good health during the experimental period. No clinical signs of inflammation or adverse tissue reactions were observed when animals were sacrificed and all cylinders were still in situ.

Fig. 3 shows the histological appearances of $\mathrm{Ti}$ and $\mathrm{Fn} / \mathrm{Ti}$ implants in the tibia (cortical bone). New bone formation was observed around implants after 12 weeks of implantation. Bone remodeling proceeded and mature bone formation was detected. Furthermore, the permeation of inflammatory cells was not observed. New bone formation was greater with Fn/Ti implants than with Ti implants and tight bone-to-implant bonding was observed for Fn/Ti implants.

Table 1 shows the percentages of BIC and BM after 12 weeks of implantation. BIC and BM were significantly higher for $\mathrm{Fn} / \mathrm{Ti}$ implants than for Ti implants $(\mathrm{p}<0.05)$.

\section{Discussion}

In the present study, we immobilized fibronectin onto a titanium implant using the tresyl chloride-activated method and evaluated the bone response against fibronectin-immobilized $\mathrm{Ti}$ implants. Implants were inserted into bone defects in rabbit tibiae for 12 weeks.

New bone formation was greater around Fn/Ti cylinder implants and histomorphometrical evaluations revealed significantly higher BIC and BM for cylindrical Fn/Ti implants than for Ti implants. Fibronectin is a well-known cell-adhesive protein and has not only a RGD sequence, but also approximately 30 independent binding domains for collagen, proteoglycan, heparin, and others. The factors affecting osteoblast activity may depend on these functional domains ${ }^{24)}$. Osteoblast attachment to titanium implants and/or osteoblast activity around implants was assumed to be enhanced and better bone responses were obtained by fibronectin immobilization; however, the underlying mechanism needs to be elucidated in more detail.

The advantage of the tresyl chloride-activated method is its ease and wide applicability. There is no need for any pretreatment of the titanium surface such as an acid or alkali treatment. Many types of proteins or cytokines may be immobilized on the titanium surface. Suzuki et al. ${ }^{22)}$ immobilized TGF- $\beta 2$ onto titanium by the tresyl chloride-activated method and found that its immobilization effectively enhanced bone regeneration around implants.

The tresyl chloride-activated method is a wet process. Thus, another advantage of this method is that proteins or cytokines may be immobilized on material with a complex surface such as a porous scaffold. In the present study, fibronectin was easily immobilized onto the cylindrical shape of the titanium implant. Amemiya et al. ${ }^{25}$ immobilized fibronectin and collagen onto a three-dimensional titanium fiber structure using the tresyl chlorideactivated method. They found that the immobilization of fibronectin or collagen was effective for internal bone augmentation, but not for external bone augmentation.

It currently remains unknown whether immobilized fibronectin is released in vivo following implantation. Suzuki et al. ${ }^{22)}$ speculated that a small amount of TGF- $\beta 2$ may be released from TGF- $\beta 2$-immobilized implants, which may, in turn, stimulate bone formation around the implants. Therefore, the stability of immobilized fibronectin needs to be determined in vivo.

In conclusion, the immobilization of fibronectin onto cylindrical titanium implants effectively enhanced bone regeneration around implants. The tresyl chloride-activated method is an innovative system to immobilize various proteins onto titanium without reductions in their bioactivities. The immobilization of other proteins or cytokines will be the next subject of our research. Furthermore, the combined immobilization of different proteins or cytokines may lead to the development of a new type of biofunctional titanium implant.

\section{Acknowledgments}

This work was supported by a Grant-in-Aid from the Society for Tsurumi University School of Dental Medicine (Grant number. 23014), and in part by Grants-in-Aid for Scientific Research (B) (15K20492) from the Japan Society for the Promotion of Science.

\section{References}

1. Albrektsson T and Wennerberg A. Oral implant surface: Part 
Masatsugu Hirota et al:: Bone Adaptation of a Fibronectin-Immobilized Titanium Implant

1-Review focusing on topographic and chemical properties of different surfaces and in vivo responses to them. Int Implants Res 16: 657-666, 2005

2. Kim HM, Miyaji F, Kokubo T and Nakamura T. Preparation of bioactive Ti and its alloys via simple chemical surface treatment. J Biomed Mater Res 32: 409-417, 1996

3. Schüpbach P, Glauser R, Rocci A, Martignoni M, Sennerby L, Lundgren A and Gottlow J. The human bone-oxidized titanium implant interface: A light microscopic, scanning electron microscopic, back-scatter scanning electron microscopic, and energy-dispersive x-ray study of clinically retrieved dental implants. Clin Implants Dent Relat Res 7: S36-43. 2005

4. Honda R, Mizutani M, Ohmori H and Komotori J. Bioompatibility evaluation of nanosecond laser treated titanium surface. Int J Mod Phys Conf Ser 6: 682-687, 2012

5. Ma C, Nagai A, Yamazaki Y, Toyama T, Tsutsumi Y, Hanawa T, Wei W and Yamashita K. Electrically polarized microarc oxidized $\mathrm{TiO}_{2}$ coatings with enhanced surface hydrophylicity. Acta Biomater 8: 860-865, 2012

6. Hirota M, Hayakawa T, Ohkubo C, Sato M, Hara H, Toyama T and Tanaka Y. Bone responses to zirconia implants with a thin carbonate-containing hydroxyapatite coating using a molecular precursor method. J Biomed Mater Res B Appl Biomater 102: 1277-1288, 2014

7. Beutner R, Michael J, Schwenzer B and Scharnweber D. Biological nano-functionalization of titanium-based biomaterial surfaces: a flexible toolbox. J R Soc Interface 7: S93-S105, 2010

8. Dean JW, Culbertson KC and D'Angelo AM. Fibronectin and laminin enhance gingival cell attachment to dental implant surfaces in vitro. J Oral Maxillofac Implants 10: 721-728, 1995

9. El-Ghannam A, Starr L and Jones J. Laminin-5 coating enhances epithelial cell attachment, spreading, and hemidesmosome assembly on Ti-6Al-4V implant material in vitro. J Biomed Mater Res 41: 30-40, 1998

10. Roehlecke C, Witt M, Kasper M, Schulze E, Wolf C, Hofer A and Funk RHW. Synergistic effect of titanium alloy and collagen typeI on cell adhesion, proliferation and differentiation of osteoblast-like cells. Cells tissues Organs 168: 178-187, 2001

11. Nagai M, Hayakawa T, Fukatsu A, Yamamoto M, Fukumoto M, Nagahama F, Mishima H, Yoshinari M, Nemoto K and Kato T. In vitro study of collagen coating of titanium implants for initial cell attachment. Dent Mater J 21: 250260, 2002

12. Culp LA and Sukenik CN. Cell type-specific modulation of fibronectin adhesion functions on chemically-derivatized self-assembled monolayers. J Biomater Sci Polym Edn 9:
1161-1176, 1998

13. Hayakawa T, Yoshinari M and Nemoto K. Direct attachment of fibronectin to tresyl chloride-activated titanium. J Biomed Mater Res A 67: 684-688, 2003

14. Nilsson K and Mosbach K. Tresyl chloride-activated supports for enzyme immobilization. Methods Enzymol 135: 65-78, 1987

15. Hayakawa T, Yoshinari M and Nemoto K. Quartz-crystal microbalance-dissipation technique for the study of initial adsorption of fibronectin onto tresyl chloride-activated titanium. J Biomed Mater Res B Appl Biomater 73: 271276, 2005

16. Hayakawa T, Nagai M, Yamamoto M, Makimura M and Nemoto K. Frontier molecular orbital study for the tresylchloride activated technique for protein coupling to titanium. Int J Oral-Med Sci 3: 20-24, 2004

17. Pugdee K, Shibata Y, Yamauchi N, Tsutsumi H, Yoshinari M, Abiko Y and Hayakawa T. Gene expression of MC3T3E1 cells on fibronectin-immobilized titanium using tresyl chloride activation technique. Dent Mater J 26: 647-655, 2007

18. Hayakawa T, Nagai M, Yoshinari M, Makimura M and Nemoto K. Cell-adhesive protein immobilization using tresyl chloride-activation technique for the enhancement of initial cell attachment. J Oral Tissue Engin 2: 14-24, 2005

19. Yoshida E, Yoshimura Y, Uo M, Yoshinari M and Hayakawa T. Influence of nanometer smoothness and fibronectin immobilization of titanium surface on MC3T3-E1 cell behavior. J Biomed Mater Res A 100A: 1556-1564, 2012

20. Yamauchi N, Pugdee K, Chang WJ, Lee SY, Yoshinari M, Hayakawa $\mathrm{T}$ and Abiko Y. Gene expression monitoring in osteoblasts on titanium coated with fibronectin-derived peptide. Dent Mater J 27: 744-750, 2008

21. Ferraris $\mathrm{S}$, Spriano $\mathrm{S}$, Bianchi CL, Cassinelli $\mathrm{C}$ and Vernè E. Surface modification of Ti-6Al-4V alloy for biomineralization and specific biological response: part II, alkaline phosphatase grafting. J Mater Sci Mater Med 22: 1835-1842, 2011

22. Suzuki T, Hayakawa T, Kawamoto T and Gomi K. Bone response of TGF- $\beta 2$ immobilized titanium in a rat model. Dent Mater J 33: 233-241, 2014

23. Donath $\mathrm{K}$ and Breuner G. A method for study of undecalcified bones and teeth with attached soft tissues: The Sage-Schliff (sawing and grinding) technique. J Oral Pathol 11: 318-326, 1982

24. Hynes RO. Integrins: bidirectional, allosteric signaling machines. Cell 110: 673-687, 2002

25. Amemiya T, Fukayo Y, Nakaoka K, Hamada Y and Hayakawa $\mathrm{T}$. Tissue response of surface-modified three-dimensional titanium fiber structure. J Hard Tissue Biol 23: 137-148, 2014 
J.Hard Tissue Biology Vol. 24(4):341 -346, 2015 